\title{
Detection of Fasciola hepatica and Fasciola gigantica common and uncommon antigens, using rabbit hyper immune serum raised against their excretory-secretory and somatic antigens
}

\author{
S. Abdolahi Khabisi ${ }^{1} \cdot$ B. Sarkari ${ }^{2}$
}

Received: 27 December 2014/Accepted: 23 September 2015/Published online: 13 January 2016

(C) Indian Society for Parasitology 2016

\begin{abstract}
Fasciolosis is an important neglected helminth disease caused by two liver flukes, Fasciola hepatica and Fasciola gigantica. The two species of Fasciola are usually different in their morphological and molecular features. They have also common and uncommon antigens in both their somatic and excretory secretory metabolites. In this study, we compared somatic and excretory-secretory (ES) antigens of $F$. hepatica and $F$. gigantica, by using rabbit hyper immune serum raised against these antigens. Adult worms were collected from bile ducts of infected animals and species of the fluke was confirmed by RFLP-PCR. ES and somatic antigens of both species were prepared. Rabbits were subcutaneously immunized with either ES or somatic antigens to produce antibodies against these antigens. SDS-PAGE pattern of $F$. hepatica and $F$. gigantica somatic antigens was similar and both of them revealed 30 protein bands, ranging from 18 to $180 \mathrm{kDa}$. In contrast, SDS-PAGE pattern of ES antigen of the two species was different. While protein bands with molecular weight of 18 , $27,29,48$, and $62 \mathrm{kDa}$ were common in both species, bands of $19,45,55$ and $58 \mathrm{kDa}$ were only noticed in $F$. hepatica ES antigen. Rabbit polyclonal antibodies, raised against $F$. hepatica and $F$. gigantica ES antigen, reacted with main five protein bands, 25, 27, 29, 62 and $67 \mathrm{kDa}$ and polyclonal antibodies raised against somatic antigens of both species reacted with three protein bands,
\end{abstract}

B. Sarkari

sarkarib@yahoo.com; sarkarib@sums.ac.ir

1 Department of Parasitology and Mycology, School of Medicine, Shiraz University of Medical Sciences, P.O. Box 71345-1735, Shiraz, Iran

2 Basic Sciences in Infectious Diseases Research Center, Shiraz University of Medical Sciences, Shiraz, Iran
25, 27 and $72 \mathrm{kDa}$. Thus, the 25, 27 and $29 \mathrm{kDa}$ protein bands may serve as immunodominant antigens, which might be considered for serodiagnosis of fasciolosis. Moreover, bands of 62 and $67 \mathrm{kDa}$ in ES antigen and $72 \mathrm{kDa}$ in somatic antigens of both species were immunodominant and might be suitable candidate for development of serological assays for diagnosis of fasciolosis.

Keywords Western blotting - Fasciola .

Somatic antigen $\cdot$ Excretory-secretory antigen

\section{Introduction}

Fasciolosis is a worldwide neglected parasitic disease of domestic animals and human (Hotez et al. 2012). The number of human fasciolosis has been increasing in the last decades in a few countries and the disease is considered as an important human parasitic infection in several areas of the world, including Bolivia, Ecuador, Peru, Viet Nam, Egypt and Iran (Soliman 2008; Rokni 2008; Sarkari et al. 2012; WHO 2010). It has been estimated that about 17 million people are infected with Fasciola spp. around the world (Mas-Coma et al. 2009).

The causative agents of both human and animal fasciolosis are two main species of the fluke, Fasciola hepatica and Fasciola gigantica. Fasciola gigantica is present mainly in tropical and $F$. hepatica in temperate areas, while both species overlapped in subtropical areas including Egypt and Iran (Soliman 2008; Mas-Coma et al. 2009; Moghaddam et al. 2004; Shafiei et al. 2014).

The two species of Fasciola are usually different in morphological features, such as body length and width. However, because of variations in size of these two species and the presence of intermediate forms, morphometric 
features are not appropriate characters for distinguishing of these two species of Fasciola. Nowadays, molecular approaches have been considered as suitable method for discrimination of the Fasciola species (Shafiei et al. 2013; Shafiei et al. 2014).

These two species of fluke have common and uncommon antigens in both their somatic and ES metabolites. Study of Meshgi revealed that $F$. hepatica and $F$. gigantica have at least six common major peptide bands in their ES products with molecular weights of 15-24 kDa (Meshgi et al. 2008). It was also demonstrated that the two species have differences in somatic proteins where $F$. gigantica had 11 major protein bands with molecular weights of $18-68 \mathrm{kDa}$ and $F$. hepatica had eight distinct bands with molecular weights of 18-62 kDa (Meshgi et al. 2008).

The common antigens of two species might be useful for diagnosis of human or animal fasciolosis when the species of the parasite is not a matter of concern, while the uncommon antigens which are different in each species, might be appropriate antigens for either diagnosis of fasciolosis, based on the species of the parasite, or for vaccine development. Different antigenic fractions of Fasciola have been used for serological diagnosis of human fasciolosis. The use of specific antigens, purified from somatic or ES products of Fasciola spp. in ELISA or immunoblotting system, yielded satisfactory sensitivity and specificity as reported in different studies (O'Neill et al. 1999; Rokni et al. 2003; Espinoza et al. 2007).

Among the subunit antigens, the Cathepsin-L, a component of Fasciola ES antigens, has received the most attention (O'Neill et al. 1999; Rokni et al. 2002). It is obvious that nature and quality of purified antigen contribute to the validity and value of serological diagnostic tests. In order to increase the sensitivity and specificity of fasciolosis diagnostic tests, isolation, purification and characterization of somatic and ES antigens of both species of Fasciola is necessary (Dalimi et al. 2004). The current study aimed to find out the common and uncommon antigens of $F$. hepatica and $F$. gigantica, using rabbit hyper immune serum raised against ES and somatic antigens of these two species of Fasciola.

\section{Materials and methods}

\section{Sample collecting}

Fasciola adult worms were obtained from bile ducts of infected animals (sheep and cattle) from local abattoirs in Shiraz, south of Iran. F. hepatica was isolated from sheep while $F$. gigantica was isolated from cattle. The worms were washed five times with PBS ( $\mathrm{pH} 7.2)$ and transferred into $70 \%$ alcohol, for molecular assay, into PBS for somatic antigen preparation, and into RPMI 1640 medium for ES antigen preparation.

\section{DNA extraction and PCR-RFLP}

Molecular identification of Fasciola species was performed as previously described (Shafiei et al. 2014). Briefly, a part of the apical and lateral zone of the adult flukes were removed and homogenized. DNA was extracted from the homogenized materials using phenol-chloroform method. PCR was performed using ITS1 forward; 5-TTGCGC TGATTACGTCCCTG-3 and reverse; 5'-TTGGCTGCGC TCTTCATCGAC-3' primers. PCR products were subjected to fast digestion with RsaI restriction enzyme. The restriction fragments were separated on $2 \%$ agarose gel and visualized with ethidium bromide.

\section{Preparation of somatic antigen}

$F$. hepatica and $F$. gigantica adult worms were used for preparation of somatic antigens. Adult worms were homogenized in PBS, using a tissue grinder. A cocktail of anti-protease was used during antigen preparation. Following homogenization, the sample was centrifuged at $13,000 \mathrm{~g}$ for $30 \mathrm{~min}$ at $4{ }^{\circ} \mathrm{C}$, supernatant was removed and stored at $-20{ }^{\circ} \mathrm{C}$ until use.

\section{Preparation of excretory-secretory (ES) antigen}

Intact flukes collected from the bile ducts of infected animals were washed five times with PBS. The worms were transferred into culture flask containing RPMI-1640 (one fluke per $1 \mathrm{ml}$ ), $100 \mathrm{IU}$ of penicillin and $100 \mu \mathrm{g} / \mathrm{ml}$ of streptomycin, and incubated at $37{ }^{\circ} \mathrm{C}$ for $14-16 \mathrm{~h}$. Afterward, worms were removed and the remaining media was centrifuged at $13,000 \mathrm{~g}$ for $30 \mathrm{~min}$. Supernatant was dialyzed against $\mathrm{PBS}$, lyophilized and stored at $-20{ }^{\circ} \mathrm{C}$ until future use.

\section{Production of Polyclonal antibodies against somatic and ES antigen}

Eight female rabbits, weighing 1.5-2 kg, were allocated in two groups and each four rabbits were subcutaneously immunized with either ES or somatic antigens. In the first injection, each rabbit received $500 \mu \mathrm{g}$ of antigens, mixed with equal volume of Freund's complete adjuvant followed by three 7 days interval of injections with Freund's incomplete adjuvant. Blood samples were collected, 10 days after the last injection, and examined by ELISA to verify anti-Fasciola antibodies. 


\section{Enzyme linked immunosorbent assay (ELISA)}

Micro plates (Nunc, Nalgene, Nunc International, Roskilde, Denmark) were coated with $5 \mu \mathrm{g} / \mathrm{ml}$ of $F$. hepatica or $F$. gigantica somatic or ES antigens in coating buffer (0.05 M carbonate-bicarbonate buffer, $\mathrm{pH}$ 9.6) and incubated at $4{ }^{\circ} \mathrm{C}$ overnight. After five times washes by phosphate buffered saline-Tween 20 (PBST, pH 7.4 containing $0.05 \%$ Tween 20 ), unbinding sites were blocked with $3 \%$ skimmed milk in PBS/Tween. The plates were washed as before and rabbit serum, at dilution of $1 / 100$, was added and incubated for $90 \mathrm{~min}$ at room temperature. The wells were washed as before, and $100 \mu \mathrm{l}$ of horseradish peroxidase (HRPO)-conjugated anti-rabbit IgG (Sigma) at 1/4000 dilution in PBST was added, and plates were incubated for $60 \mathrm{~min}$ at RT. After washing as before, the plates were incubated with chromogen/substrate $(100 \mu \mathrm{l} /$ well of OPD, $0.025 \% \mathrm{H}_{2} \mathrm{O}_{2}$ in $0.1 \mathrm{M}$ citrate buffer, $\mathrm{pH}$ 5). The absorbance at $490 \mathrm{~nm}$ was checked with an ELISA microplate reader.

\section{SDS-PAGE and western blotting assay}

$F$. hepatica and $F$. gigantica ES and somatic antigens were separated by SDS-PAGE and evaluated by rabbit hyper immune serum, raised against each antigen. SDS-PAGE was performed under reducing condition using $12 \%$ separating gel and $5 \%$ stacking gel in a Bio-Rad apparatus at $25 \mathrm{~mA} / \mathrm{gel}$ for $1 \mathrm{~h}$. Separated antigen was transferred to nitrocellulose membrane, and the membrane was embedded in $5 \%$ skimmed milk, as blocking solution, for $2 \mathrm{~h}$. The membrane was washed by washing buffer $(10 \mathrm{mM}$ Tris, $150 \mathrm{mM} \mathrm{NaCl}$, and $0.05 \%$ Tween 20; pH 7.4). Each of produced rabbit hyper immune serum [1/100 dilution in washing buffer with $1 \%$ bovine serum albumin (BSA)], were applied to the membrane and incubated for $90 \mathrm{~min}$. After three washes (10 min each), peroxidase conjugated anti-rabbit IgG (Sigma) at dilution of $1 / 4000$ was added and incubated for $60 \mathrm{~min}$ at RT. After three washes, as before, the reaction between antigen and antibody was visualized by adding diaminobenzidine (DAB) substrate $\left(0.1 \% \mathrm{H}_{2} \mathrm{O}_{2}+1 \mathrm{mg} / \mathrm{ml}\right.$ DAB in $50 \mathrm{mM}$ Tris- $\mathrm{HCl}$, $\mathrm{pH}$ 7.6).

\section{Results}

\section{SDS-PAGE pattern of $F$. hepatica and $F$. gigantica somatic and ES antigens}

SDS-PAGE pattern of $F$. hepatica and $F$. gigantica somatic antigens were somewhat similar where both antigens revealed 30 protein bands ranging from 18 to $180 \mathrm{kDa}$.
Intensities of some protein bands including 22.5, 27, 31 and $62 \mathrm{kDa}$ in SDS-PAGE pattern of $F$. gigantic somatic antigen was higher than $F$. hepatica somatic antigen. In addition, intensities of 31 and $53 \mathrm{kDa}$ protein bands of $F$. hepatica somatic antigens were strongly higher than those of $F$. gigantica. In both species $25,37.5$ and $41 \mathrm{kDa}$ protein bands revealed high intensities in comparison to other protein bands (Fig. 1).

SDS-PAGE pattern of ES antigens of two species was different. Protein bands with molecular weights of 18, 27, 29,48 and $62 \mathrm{kDa}$ were common in both species whereas protein bands of $19,45,55$ and $58 \mathrm{kDa}$ were only detected in $F$. hepatica $\mathrm{ES}$ antigens. The number of protein bands of ES antigen in comparison to somatic antigen was less and all of nine protein bands of ES antigens (18, 19, 27, 29, 45, $48,55,58$, and 62 ) were available in somatic antigens of both species.

\section{Western blotting analysis of ES and somatic antigens}

Polyclonal antibodies raised against $F$. hepatica somatic antigen detected 17 bands ranging from 22.5 to $180 \mathrm{kDa}$, whereas polyclonal antibodies to $F$. hepatica ES antigen detected 11 bands, ranging from 25 to $180 \mathrm{kDa}$ in somatic antigen of $F$. hepatica. Polyclonal antibodies raised against $F$. gigantica somatic antigen detected 13 bands ranging from 25 to $135 \mathrm{kDa}$ and polyclonal antibodies raised against $F$. gigantica $\mathrm{ES}$ antigen detected 11 bands ranging from 22.5 to $180 \mathrm{kDa}$ in $F$. hepatica somatic antigen. All of produced polyclonal antibodies commonly detected bands of $25,27,62,72$, and $135 \mathrm{kDa}$ in $F$. hepatica somatic antigen.

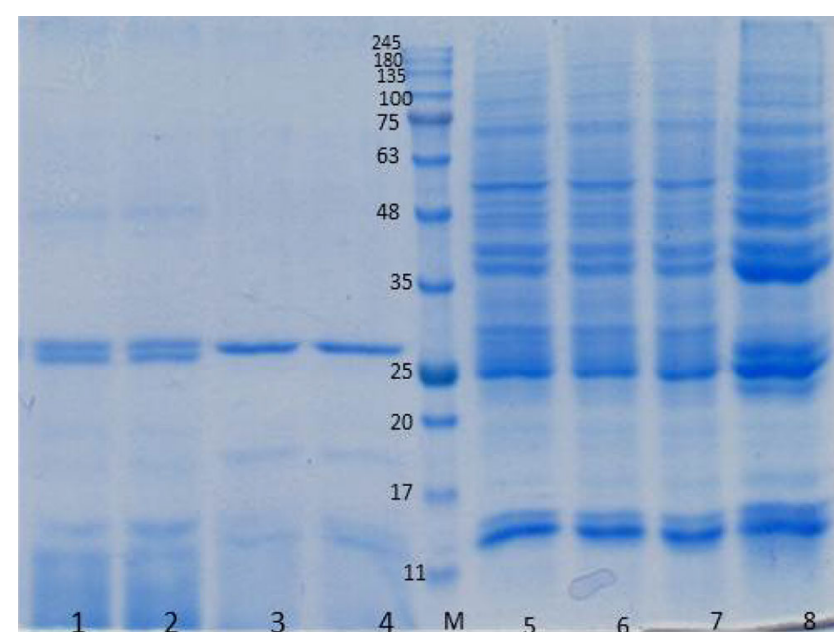

Fig. 1 SDS-PAGE pattern of $F$. hepatica and $F$. gigantica somatic and ES antigens stained with Coomaassie Brilliant Blue stain. 1 and 2 $F$. hepatica ES antigen; 3 and $4 F$. gigantica ES antigen; 5, 6 and 7 $F$. hepatica somatic antigen; $8 \mathrm{~F}$. gigantica somatic antigen 
Table 1 Detected protein bands in western blotting on $F$. hepatica ES antigen (h) and $F$. gigantica ES antigen (g) with rabbit polyclonal antibodies raised against $F$. hepatica somatic antigen, $F$. gigantica somatic antigen, $F$. hepatica ES antigen and $F$. gigantica ES antigen

\begin{tabular}{|c|c|c|c|c|c|c|c|c|c|c|c|c|c|c|c|c|c|c|c|c|c|c|c|c|}
\hline \multirow{2}{*}{$\begin{array}{l}\text { Antigen } \\
\text { molecular weight } \\
\text { (kDa) } \\
\text { Polyclonal } \\
\text { antibodies against }\end{array}$} & \multicolumn{2}{|l|}{18} & \multicolumn{2}{|c|}{19} & \multicolumn{2}{|c|}{25} & \multicolumn{2}{|c|}{27} & \multicolumn{2}{|c|}{29} & \multicolumn{2}{|l|}{45} & \multicolumn{2}{|c|}{48} & \multicolumn{2}{|c|}{55} & \multicolumn{2}{|c|}{57} & \multicolumn{2}{|l|}{62} & \multicolumn{2}{|l|}{67} & \multicolumn{2}{|c|}{135} \\
\hline & $\mathrm{g}$ & $\mathrm{h}$ & $\mathrm{g}$ & $\mathrm{h}$ & $\mathrm{g}$ & $\mathrm{h}$ & $\mathrm{g}$ & $\mathrm{h}$ & $\mathrm{g}$ & $\mathrm{h}$ & $\mathrm{g}$ & $\mathrm{h}$ & $\mathrm{g}$ & $\mathrm{h}$ & $\mathrm{g}$ & $\mathrm{h}$ & $\mathrm{g}$ & $\mathrm{h}$ & $\mathrm{g}$ & $\mathrm{h}$ & $\mathrm{g}$ & $\mathrm{h}$ & $\mathrm{g}$ & $\mathrm{h}$ \\
\hline $\begin{array}{l}F . \text { hepatica } \\
\text { somatic antigen }\end{array}$ & - & - & - & - & + & + & + & + & + & + & + & - & + & - & - & + & - & + & + & + & + & + & + & - \\
\hline $\begin{array}{l}F . \text { gigantica } \\
\text { somatic antigen }\end{array}$ & + & - & - & - & + & + & + & + & + & + & + & - & + & - & - & + & - & + & + & + & + & + & + & - \\
\hline $\begin{array}{l}F \text {. hepatica } \mathrm{E} / \mathrm{S} \\
\text { antigen }\end{array}$ & - & + & - & + & + & + & + & + & + & + & - & - & - & - & - & - & - & - & + & + & + & + & + & + \\
\hline $\begin{array}{l}F . \text { gigantica } \mathrm{E} / \mathrm{S} \\
\text { antigen }\end{array}$ & + & + & - & + & + & + & + & + & + & + & + & - & + & - & - & - & - & - & + & + & + & + & + & \\
\hline
\end{tabular}

Antibodies raised against $F$. gigantica somatic antigen detected 19 bands with different molecular weight, varies from 20 to $180 \mathrm{kDa}$ while antibodies raised against $F$. hepatica somatic antigen detected 15 bands with molecular weight of $20-180 \mathrm{kDa}$. Antibodies raised against $F$. gigantica $\mathrm{ES}$ antigen detected 21 and antibodies raised against $F$. hepatica ES antigen detected 16 bands in somatic antigen of $F$. gigantica. All of produced polyclonal antibodies commonly detected bands of 25, 27, 37.5, 39.5, $45,48,72$ and $180 \mathrm{kDa}$ in $F$. gigantica somatic antigens.

Antibodies raised against $F$. hepatica ES antigen detected six bands and antibodies raised against $F$. gigantica ES antigen detected seven bands in ES antigen of $F$. hepatica. Antibodies raised against $F$. hepatica and $F$. gigantica somatic antigens detected seven bands in ES antigen of $F$. hepatica ranging from 25 to $67 \mathrm{kDa}$. All of produced polyclonal antibodies commonly detected bands of 25, 27, 29, 62, and 67 in ES antigen of $F$. hepatica.

Antibodies raised against $F$. gigantica $\mathrm{ES}$ antigen detected nine different bands with molecular weight of $18-135 \mathrm{kDa}$, whereas antibodies raised against $F$. hepatica ES antigen detected six bands of $25-135 \mathrm{kDa}$. Antibodies to $F$. gigantica somatic antigen reacted with ten bands of 18-135 kDa while antibodies against $F$. hepatica somatic antigen reacted with eight bands of $25-135 \mathrm{kDa}$. All of produced polyclonal antibodies commonly reacted with bands of 25, 27, 29, 62, 67 and $135 \mathrm{kDa}$ of $F$. gigantica ES antigen. Tables 1 and 2 show the details of different components of ES and somatic antigens of $F$. hepatica and $F$. gigantica, detected by rabbit antibodies, raised against these antigens.

\section{Discussion}

Different antigens of Fasciola including somatic, ES, recombinant and tegumental antigens have been used for immunodiagnosis of human or animal fasciolosis (Morales and Espino 2012; Rokni et al. 2003; Shafiei et al. 2015). The present study was carried out to determine common antigens of $F$. hepatica and $F$. gigantica somatic and ES antigens, using rabbit polyclonal antibodies raised against these two sets of antigens.

Species specific or common antigens of $F$. hepatica and $F$. gigantica have been reported in different studies. Meshgi et al. (2008) showed the presence of 11 (ranging from 18 to $68 \mathrm{kDs}$ ) protein bands in somatic antigens of $F$. gigantica and 8 (ranging from 18 to $62 \mathrm{kDs}$ ) protein bands in somatic antigens of $F$. hepatica. Maleewong et al. (1997) and Velusamy et al. (2006) respectively reported 11 (ranging from 14 to $94 \mathrm{kDa}$ ) and 23 (ranging from 12 to $96 \mathrm{kDa}$ ) protein bands in SDS-PAGE of $F$. gigantica somatic antigens.

Allam et al. (2002) and Gonence and Sarimehmetoglu (2004) in two different studies reported fewer protein bands in SDS-PAGE pattern of Fasciola in comparison to our study. Study of Yokananth et al. (2005), about electrophoretic separation of $F$. gigantica somatic antigen, showed 20 protein bands (ranging from 14 to $156 \mathrm{kDa}$ ) (Yokananth et al. 2005). Eight protein bands reported in their study are common with those that we are seeing in the current study. De Almeida et al. (2007) reported 17 protein bands (ranging from 2 to $80 \mathrm{kDa}$ ) in $F$. hepatica somatic antigen (De Almeida et al. 2007).

Meshgi et al. (2008) reported six common protein bands (ranging from 15 to $42 \mathrm{kDa}$ ) for SDS PAGE pattern of both $F$. hepatica and $F$. gigantica ES antigens. In a study by Gonenc et al. (2004) 23 protein bands (ranging from 6.5 to $205 \mathrm{kDa}$ ) for $F$. hepatica ES antigen have been reported. De Almeida et al. reported 19 protein bands (ranging from 2 to $80 \mathrm{kDa}$ ) for $F$. hepatica vomiting antigen (ES antigen) (De Almeida et al. 2007). In the current study, five and nine protein bands have been respectively detected in $F$. hepatica and $F$. gigantica ES antigens. Differences in number and molecular weight of reported protein bands of ES or 
Table 2 Detected protein bands in western blotting on $F$. hepatica somatic antigen $(\mathrm{h})$ and $F$. gigantica somatic antigen $(\mathrm{g})$ with rabbit polyclonal antibodies raised against $F$. hepatica somatic antigen,
$F$. gigantica somatic antigen, $F$. hepatica ES antigen and $F$. gigantica ES antigen

\begin{tabular}{|c|c|c|c|c|c|c|c|c|c|c|c|c|c|c|c|c|c|c|c|c|c|c|c|c|c|c|c|c|c|}
\hline \multirow{2}{*}{$\begin{array}{l}\text { Antigen } \\
\text { molecular } \\
\text { weight }(\mathrm{kD}) \\
\text { Polyclonal } \\
\text { antibodies } \\
\text { against }\end{array}$} & \multicolumn{2}{|c|}{20} & \multicolumn{2}{|c|}{22.5} & \multicolumn{2}{|c|}{25} & \multicolumn{2}{|l|}{27} & \multicolumn{3}{|c|}{31} & \multicolumn{2}{|l|}{32} & \multicolumn{2}{|c|}{33.5} & \multicolumn{2}{|c|}{35} & \multicolumn{3}{|c|}{37.5} & \multicolumn{2}{|c|}{39.5} & \multicolumn{2}{|c|}{41} & \multicolumn{3}{|c|}{43} & \multicolumn{2}{|l|}{45} \\
\hline & $\mathrm{g}$ & $\mathrm{h}$ & $\mathrm{g}$ & $\mathrm{h}$ & $\mathrm{g}$ & $\mathrm{h}$ & $\mathrm{g}$ & $\mathrm{h}$ & $\mathrm{g}$ & 1 & a & $\mathrm{g}$ & $\mathrm{h}$ & $\mathrm{g}$ & $\mathrm{h}$ & $\mathrm{g}$ & $\mathrm{h}$ & $\mathrm{g}$ & g & $\mathrm{h}$ & $\mathrm{g}$ & $\mathrm{h}$ & $\mathrm{g}$ & $\mathrm{h}$ & $\mathrm{g}$ & $\mathrm{h}$ & & $\mathrm{g}$ & $\mathrm{h}$ \\
\hline $\begin{array}{c}F \text {. hepaticas } \\
\text { somatic } \\
\text { antigen }\end{array}$ & + & - & - & + & + & + & + & + & - & - & - & - & + & - & - & - & - & & + & + & + & - & - & + & - & - & & + & + \\
\hline $\begin{array}{c}F . \text { gigantica } \\
\text { somatic } \\
\text { antigen }\end{array}$ & + & - & + & - & + & + & + & + & - & - & + & - & + & - & - & + & - & + & + & + & + & + & - & + & - & - & & + & - \\
\hline $\begin{array}{l}\text { F. hepatica } \mathrm{E} / \mathrm{S} \\
\text { antigen }\end{array}$ & - & - & - & - & + & + & + & + & + & - & + & - & - & + & - & - & - & + & + & - & + & - & - & + & + & - & & + & - \\
\hline $\begin{array}{l}F . \text { gigantica } \\
\text { E/S antigen }\end{array}$ & - & - & - & + & + & + & + & + & + & - & - & + & - & - & - & + & - & + & + & - & + & - & - & + & + & - & & + & - \\
\hline \multicolumn{4}{|c|}{ Antigen molecular weight (kD) } & \multicolumn{2}{|l|}{48} & \multicolumn{2}{|l|}{51} & \multicolumn{2}{|l|}{53} & \multicolumn{2}{|c|}{55} & \multicolumn{2}{|c|}{57} & \multicolumn{2}{|c|}{62} & \multicolumn{2}{|l|}{67} & \multicolumn{2}{|l|}{72} & \multicolumn{2}{|l|}{75} & \multicolumn{2}{|l|}{90} & \multicolumn{2}{|l|}{110} & \multicolumn{2}{|l|}{135} & \multicolumn{2}{|c|}{180} \\
\hline Polyclonal antib & dies & aga & & $\mathrm{g}$ & $\mathrm{h}$ & $\mathrm{g}$ & $\mathrm{h}$ & $\mathrm{g}$ & $\mathrm{h}$ & $\mathrm{g}$ & $\mathrm{h}$ & $\mathrm{g}$ & $\mathrm{h}$ & $\mathrm{g}$ & $\mathrm{h}$ & $\mathrm{g}$ & $\mathrm{h}$ & $\mathrm{g}$ & $\mathrm{h}$ & $\mathrm{g}$ & $\mathrm{h}$ & $\mathrm{g}$ & $\mathrm{h}$ & $\mathrm{g}$ & $\mathrm{h}$ & $\mathrm{g}$ & $\mathrm{h}$ & $\mathrm{g}$ & $\mathrm{h}$ \\
\hline F. hepaticas son & atic & anti & & + & + & - & + & - & + & + & + & + & - & - & + & - & - & + & + & + & + & + & + & + & - & + & + & + & + \\
\hline F. gigantica som & atic & intig & & + & - & + & - & + & - & - & - & + & + & - & + & + & + & + & + & + & - & + & + & + & - & + & + & + & - \\
\hline F. hepatica $\mathrm{E} / \mathrm{S}$ & antig & & & + & - & + & - & - & + & - & + & - & - & + & + & + & + & + & + & + & - & - & - & + & - & - & + & + & + \\
\hline F. gigantica $\mathrm{E} / \mathrm{S}$ & anti & & & + & _ & + & - & + & + & _- & + & + & _ & + & + & + & + & + & + & + & - & + & _ & + & - & + & + & + & + \\
\hline
\end{tabular}

somatic antigens of Fasciola spp. in various studies might be related to differences in the adult worms which have been isolated from different hosts.

In study of Gonence and Sarimehmetoglu (2004) serum of infected sheep, with $F$. hepatica, reacted with protein bands of $24,33,35,44-55$, and $66 \mathrm{kDa}$ of $F$. hepatica somatic antigen, and protein bands of 24, 33, 39.5, 42 and 44-55 kDa of $F$. hepatica ES antigen. In other study, serum of human infected with $F$. hepatica reacted with bands of $8,12,15$, and $24 \mathrm{kDa}$ in western blotting on $F$. hepatica vomiting antigen (De Almeida et al. 2007). In our study, rabbit polyclonal antibodies to $F$. hepatica ES antigen detected 11 bands in $F$. hepatica somatic and ES antigen, most of them are different from those reported by De Almeida et al. (2007).

It has been shown that sera of cattle, sheep and buffalo, infected with $F$. gigantica, reacted respectively with 5,8 and 11 protein bands of $F$. gigantica somatic antigen (Yokananth et al. 2005). In the present study rabbit polyclonal antibodies raised against $F$. gigantica somatic and ES antigen respectively reacted with 19 and 21 protein bands of $F$. gigantica somatic antigen. Source of infection (natural or experimental infection) might contribute to the detection of different protein bands in somatic or ES antigens of adult worm. In natural infection, hosts are temporary exposed to ES antigens but this does not happen in experimental infection or in immunized hosts.
Several studies pointed out that a $27 \mathrm{kDa}$ protein band is an immunodominant protein band of ES and somatic antigens of Fasciola (Santiago and Hillyer 1988; Attallah et al. 2002; Dixit et al. 2008; Kamel et al. 2013; Intapan et al. 1998). However, in few studies, a $29 \mathrm{kDa}$ protein band has been suggested as a principle protein band of Fasciola ES antigen for diagnosis of fasciolosis (Sampaio Silva et al. 1996; Hammami et al. 1997; Rokni et al. 2004). In our study, all of produced polyclonal antibodies, against ES and somatic antigens of $F$. hepatica and $F$. gigantica, commonly reacted with the $27 \mathrm{kDa}$ protein band in western blotting on somatic or ES antigen of both species of Fasciola. In addition, a $25-\mathrm{kDa}$ protein band was commonly detected in both ES and somatic antigens by all of produced polyclonal antibodies.

Taken together, in the present study rabbit polyclonal antibodies, raised against $F$. hepatica and $F$. gigantica ES antigen reacted with main five protein bands and polyclonal antibodies raised against somatic antigens of both species reacted with three protein bands (25, 27 and $72 \mathrm{kDa}$ ). Accordingly, the 25, 27 and $29 \mathrm{kDa}$ protein bands may serve as immunodominant antigens that can be considered for serodiagnosis of fasciolosis. Moreover, bands of 62 and $67 \mathrm{kDa}$ in $\mathrm{ES}$ antigen and $72 \mathrm{kDa}$ in somatic antigens can be considered as immunodominant antigens and might be suitable candidates for development of serological assays for diagnosis of fasciolosis. 
Acknowledgments The results described in this paper were a part of Ph.D. thesis of Samaneh Abdolahi Khabisi. The study was financially supported by the office of vice-chancellor for research of Shiraz University of Medical Sciences (Grants Nos. 4261 and 6808).

\section{Compliance with ethical standards}

Conflict of interest None.

\section{References}

Allam AF, El Sayed I, Helmy MH (2002) Molecular and immunological characterization of Fasciola species. Br J Biomed Sci 59:191-195

Attallah AM, Karawia EA, Ismail H, Tabll AA, Nawar AA, Ragab WA, Abdel Aziz MM, El-Dosoky I (2002) Identification and characterization of a $26-$ to $28-\mathrm{kDa}$ circulating antigen of Fasciola gigantica. Ann Trop Med Parasitol 96:271-282

Dalimi A, Hadighi R, Madani R (2004) Partially purified fraction (PPF) antigen from adult Fasciola gigantica for the serodiagnosis of human fascioliasis using Dot-ELISA technique. Ann Saudi Med 24:18-20

De Almeida MA, Ferreira MB, Planchart S, Terashima A, Maco V, Marcos L, Gotuzzo E, Sánchez E, Náquira C, Scorza JV, Incani RN (2007) Preliminary antigenic characterizations of an adult worm vomit preparation of Fasciola hepatica by infected human sera. Rev Inst Med Trop Sao Paulo 49:31-35

Dixit AK, Dixit P, Sharma RL (2008) Immunodiagnostic/protective role of cathepsin L cysteine proteinases secreted by Fasciola species. Vet Parasitol 154:177-184

Espinoza JR, Maco V, Marcos L, Saez S, Neyra V, Terashima A, Samalvides F, Gotuzzo E, Chavarry E, Huaman MC, Bargues MD, Valero MA, Mas-Coma S (2007) Evaluation of Fas2ELISA for the serological detection of Fasciola hepatica infection in humans. Am J Trop Med Hyg 76:977-982

Gonence B, Sarimehmetoglu H (2004) Comparison of crude and excretory/secretory antigens for the diagnosis of Fasciola hepatica in sheep by western blotting. Turk J Vet Anim Sci 28:943-949

Hammami H, Ayadi A, Camus D, Dutoit E (1997) Diagnostic value of the demonstration of specific antigen of Fasciola hepatica by western blot technique. J Parasitol 4:291-295

Hotez PJ, Savioli L, Fenwick A (2012) Neglected tropical diseases of the Middle East and North Africa: review of their prevalence, distribution, and opportunities for control. PLoS Negl Trop Dis 6:e1475

Intapan PM, Maleewong W, Wongkham C, Tomanakarn K, Ieamviteevanich K, Pipitgool V, Sukolapong V (1998) Excretorysecretory antigenic components of adult Fasciola gigantica recognized by infected human sera. Southeast Asian J Trop Med Public Health 29:579-583

Kamel HH, Saad GA, Sarhan RM (2013) Dot-blot immunoassay of Fasciola gigantic infection using $27 \mathrm{kDa}$ and adult worm regurge antigens in Egyptian patients. Korean $\mathrm{J}$ Parasitol $51: 177-182$

Maleewong W, Intapan PM, Tomanakarn K, Wongkham C (1997) Antigenic components of somatic extract from adult Fasciola gigantica recognized by infected human sera. Asian Pac J Allergy Immunol 15:213-218

Mas-Coma S, Valero MA, Bargues MD (2009) Fasciola, lymnaeids and human fascioliasis, with a global overview on disease transmission, epidemiology, evolutionary genetics, molecular epidemiology and control. Adv Parasitol 69:41-146
Meshgi B, Eslami A, Hemmatzadeh F (2008) Determination of somatic and excretory-secretory antigens of Fasciola hepatica and Fasciola gigantica using SDS-PAGE. Iran J Vet Res 9:77-80

Moghaddam AS, Massoud J, Mahmoodi M, Mahvi AH, Periago MV, Artigas P, Fuentes MV, Bargues MD, Mas-Coma S (2004) Human and animal fascioliasis in Mazandaran province, Northern Iran. Parasitol Res 94:61-69

Morales A, Espino AM (2012) Evaluation and characterization of Fasciola hepatica tegument protein extract for serodiagnosis of human fascioliasis. Clin Vaccine Immunol 19:1870-1878

O’Neill SM, Parkinson M, Dowd AJ, Strauss W, Angles R, Dalton JP (1999) Immunodiagnosis of human fascioliasis using recombinant Fasciola hepatica cathepsin L1 cysteine proteinase. Am J Trop Med Hyg 60:749-751

Rokni MB (2008) The present status of human helminthic diseases in Iran. Ann Trop Med Parasitol 102:283-295

Rokni MB, Massoud J, O’Neill SM, Parkinson M, Dalton JP (2002) Diagnosis of human fasciolosis in the Gilan province of Northern Iran: application of cathepsin L-ELISA. Diagn Microbiol Infect Dis 44:175-179

Rokni MB, Massoud J, Hanilo A (2003) Comparison of adult somatic and cysteine proteinase antigens of Fasciola gigantica in enzyme linked immunosorbent assay for serodiagnosis of human fasciolosis. Acta Trop 88:69-75

Rokni MB, Baghernejad A, Mohebali M, Kia EB (2004) Enzymelinked immunotransfer blot analysis of somatic and excretorysecretory antigens of Fasciola hepatica in diagnosis of human fasciolosis. Iranian J Publ Health 33:8-13

Sampaio Silva M, Correia da Costa J, Viana da Costa AM, Pires MA, Lopes SA, Am Castro, Monjour L (1996) Antigenic components of excretory secretory products of adult Fasciola hepatica recognized in human infection. J Trop Med Hyg 54:146-148

Santiago N, Hillyer GV (1988) Antibody profiles by EITB and ELISA of cattle and sheep infected with Fasciola hepatica. J Parasitol 74:810-818

Sarkari B, Ghobakhloo N, Moshfea A, Eilami O (2012) Seroprevalence of human fasciolosis in a new-emerging focus of fasciolosis in Yasuj district, southwest of Iran. Iran J Parasitol $7: 15-20$

Shafiei R, Sarkari B, Moshfe A (2013) Consistent PCR-RFLP assay based on ITS-2 ribosomal DNA for differentiation of Fasciola species. Iran J Basic Med Sci 16:1266-1269

Shafiei R, Sarkari B, Sadjjadi SM, Mowlavi GR, Moshfe A (2014) Molecular and morphological characterization of Fasciola spp. isolated from different host species in a newly emerging focus of human fascioliasis in Iran. Vet Med Int 2014:405740

Shafiei R, Sarkari B, Sadjjadi SM (2015) Performance of a $27 \mathrm{kDa}$ Fasciola hepatica antigen in the diagnosis of human fascioliasis. J Lab Physicians 7:17-20

Soliman MF (2008) Epidemiological review of human and animal fascioliasis in Egypt. J Infect Dev Ctries 2:182-189

Velusamy R, Singh BP, Ghosh S, Chandra D, Raina OK, Gupta SC, Jayraw AK (2006) Prepatent detection of Fasciola gigantica infection in bovine calves using metacercarial antigen. Indian J Exp Biol 44:749-753

WHO (2010) The "neglected" worms. Action against worms. December 2007, Issue 10

Yokananth S, Ghosh S, Gupta SC, Suresh MG, Saravanan D (2005) Characterization of specific and cross-reacting antigens of Fasciola gigantica by immunoblotting. Parasitol Res 97:41-48 